\title{
Manejo do Solo e da Irrigação como Nova Tática de Controle de Meloidogyne incognita em Feijoeiro*
}

\author{
Marcos Roberto Dutra \& Vicente Paulo Campos \\ Universidade Federal de Lavras, Departamento de Fitopatologia, Laboratório de Nematologia, Cx. Postal 37, 37200-000, \\ Lavras, MG, Brasil, e-mail: mrdutra@ufla.br
}

(Aceito para publicação em 27/06/2003)

Autor para correspondência: Marcos R. Dutra

DUTRA, M.R. \& CAMPOS, V.P. Manejo do solo e da irrigação como nova tática de controle de Meloidogyne incognita em feijoeiro. Fitopatologia Brasileira 28:608-614. 2003.

\section{RESUMO}

A população de Meloidogyne incognita e sua infetividade foram estudadas em parcelas amostradas a zero, dois e 14 dias após o revolvimento do solo com ou sem irrigação, irrigadas sem revolvimento e testemunha. $\mathrm{Na}$ amostragem aos dois dias após a instalação do ensaio, ocorreu maior redução $(\mathrm{P} \leq 0,01)$ de juvenis do segundo estádio $\left(\mathrm{J}_{2}\right)$ no solo apenas revolvido seguido pelo revolvido e irrigado. A infetividade do inóculo do solo, contudo, foi menor $(\mathrm{P} \leq 0,01)$ quando se revolveu e irrigou o solo comparado com aquele apenas revolvido. Aos 14 dias, a menor $(\mathrm{P} \leq 0,01)$ população de $\mathrm{J}_{2}$ foi observada no solo revolvido e irrigado, seguido do revolvido, e elevada naquele apenas irrigado e na testemunha. A infetividade do inóculo do solo aos 14 dias continuou mais baixa no solo revolvido e irrigado. Aos 45 dias após a semeadura, a população de $\mathrm{J}_{2}$ continuou mais baixa
$(\mathrm{P} \leq 0,01)$ onde o solo foi revolvido e irrigado. O número de ovos por feijoeiro (Phaseolus vulgaris) no campo aos 90 dias também foi mais baixo $(\mathrm{P} \leq 0,01)$ no solo revolvido e irrigado. Maior $(\mathrm{P} \leq 0,01)$ peso das raízes e da parte aérea dos feijoeiros no campo foi observado em plantas crescidas em solo apenas revolvido, e no revolvido e irrigado A produção de feijão no solo revolvido e irrigado posteriormente foi quatro vezes maior que a testemunha, porém todos os tratamentos diferiram-se entre si. A irrigação como prática agrícola para aumentar a eficácia do alqueive no controle de fitonematóides tem sido postulada por alguns pesquisadores, mas nunca provada experimentalmente, o que agora foi realizada.

Palavras-chave adicionais: revolvimento, controle de fitonematóides, Phaseolus vulgaris.

\section{ABSTRACT}

Soil and water management as a new tactic, for controlling Meloidogyne incognita in Phaseolus vulgaris

Population of Meloidogyne incognita were evaluated in the soil and by biotesting. The population fluctuation of M. incognita was also studied during the beans (Phaseolus vulgaris) life cycle. Two days after the treatments in the field, plowing, without irrigation was found to be the most efficient in reducing $\mathrm{J}_{2}$ population ( $\left.\mathrm{P} \leq 0,01\right)$, followed by plowed-irrigated plots. The soil inoculum infectivity, however, was lower $(\mathrm{P} \leq 0,01)$ in plowed-irrigated plots than in plowed soil only. At 14 days, the lowest $(\mathrm{P} \leq 0,01) \mathrm{J}_{2}$ population was observed in plowed-irrigated plots, followed by plowed soil. The infectivity at 14 days was different $(\mathrm{P} \leq 0,01)$ for all treatments, but lowest $(\mathrm{P} \leq 0,01)$ in plowed-irrigated plots. At 45 days after bean planting in the field, the $\mathrm{J}_{2}$ population in soil was, also, different $(\mathrm{P} \leq 0,01)$ for all treatments, but still the lowest $(\mathrm{P} \leq 0,01)$ in plowed-irrigated soil 14 days before seeding. At 90 days, in the field, the numbers of eggs and egg-masses per bean plant, and the numbers of $\mathrm{J}_{2}$ in the soil were also the lowest $(\mathrm{P} \leq 0,01)$ in plowed-irrigated plots. The root and shoot weight of field bean in plowed and plowed-irrigated plots were equally $(\mathrm{P} \leq 0,01)$ high, but higher $(\mathrm{P} \leq 0,01)$ than in control and in only irrigated plots. Crop yield was different in all treatments $(\mathrm{P} \leq 0,01)$. The greatest $(\mathrm{P} \leq 0,01)$ bean yield occurred in plowed-irrigated plots 14 days before seeding with an increased productivity of four times compared to the control. Irrigation as a way of increasing effectiveness against plant parasitic nematodes has been previously postulated but never proved experimentally, as it was accomplished in this work.

\section{INTRODUÇÃO}

O feijoeiro (Phaseolus vulgaris L.) é um bom hospedeiro de Meloidogyne incognita (Kofoid \& Write) e M. javanica (Treub) (Vieira, 1993). As perdas devido ao ataque de nematóides podem chegar a 50-90\% (Zaumeyer \& Thomas, 1957; Freire \& Ferraz, 1977; Agudelo, 1980).

$\mathrm{O}$ alqueive ou pousio, realizado em campo após a eliminação das raízes das plantas infetadas, é eficaz na redução populacional de Meloidogyne spp., mesmo quando realizado

\footnotetext{
*Parte da Dissertação de Mestrado do primeiro autor. Universidade
} Federal de Lavras (2002). Pesquisa financiada pelo CNPq e FAPEMIG. por um curto período. Campos (1987) e Di Vito \& Carella (1985) alcançaram redução de $63 \%$ e $86,7 \%$ nas populações de $M$. javanica em tomateiro (Lycopersicon esculentum Mill) e de M. incognita em pimentão (Capsicum annuum L.), respectivamente, aos 30 dias após a eliminação das plantas atacadas. Também, o simples revolvimento do solo eliminou $54 \%$ da população de $M$. javanica remanescente no solo num período de 72 h (Dutra \& Campos, 1998).

A rotação com cultura não hospedeira é outro método de controle dos nematóides de galhas, recomendado em culturas como feijoeiro (Vieira, 1993; Paula \& Zambolim, 1998). Entretanto, por questões econômicas, muitos produtores não 
aceitam fazê-la, ou mesmo deixar o terreno por períodos longos de pousio, pois querem maximizar o uso do solo, principalmente em áreas irrigadas.

O período necessário para a multiplicação celular e o desenvolvimento embrionar dentro do ovo dos nematóides de galhas, em condições ideais de temperatura e umidade, é de 14 dias (Lee \& Atkinson, 1977), culminando com a saída do juvenil de segundo estádio $\left(\mathrm{J}_{2}\right)$ do ovo, levando consigo reservas energéticas corporais basicamente lipídicas e glicogênicas (Chitwood, 1998), cuja perda de parte dela leva à redução da sua infetividade (Van Gundy et al., 1967). Além disto, o J necessita ter o corpo envolto por uma película de água. Essas fragilidades do $\mathrm{J}_{2}$ poderão ser exploradas em novas medidas de controle desses patógenos.

A região Sudeste do Brasil, com inverno frio e seco contrastando com o verão, impõe condições desfavoráveis para o crescimento populacional de fitonematóides e o desenvolvimento de plantas no campo, levando os nematóides de galhas (Meloidogyne spp.) a sobreviverem no estádio de ovo no solo. A temperatura, contudo, não permanece baixa durante todo o inverno, existindo períodos com temperaturas adequadas ao desenvolvimento embrionário, o que leva grande parte da população desses patógenos à condição de $\mathrm{J}_{2}$ dentro do ovo, permanecendo sem eclodir devido às restrições de temperatura e/ou umidade (Starr, 1993; Campos et al., 2001). Vrain \& Barker (1978) e Goodell \& Ferris (1989), trabalhando com ovos de $M$. incognita, verificaram boa eclosão em temperaturas acima de $18^{\circ} \mathrm{C}$, restrita a $12^{\circ} \mathrm{C}$ e inibida abaixo de $10^{\circ} \mathrm{C}$. A umidade é outro fator que pode limitar o crescimento populacional de fitonematóides não só no inverno, mas também em períodos de interrupção de chuvas no verão, denominados veranico. Queda da umidade do solo a $-300 \mathrm{KPa}$ (solo seco) inibe a eclosão, levando à sobrevivência de juvenis dentro dos ovos (Goodell \& Ferris, 1989), prontos a eclodir após a superação desse fator limitante. Alguns pesquisadores têm lançado a hipótese de pousio úmido, isto é, irrigação do solo durante o pousio para o controle de fitonematóides, porém, sem comprovação experimental (Wallace, 1968; Apt, 1976). Starr (1993) observou que baixa umidade do solo inibe a eclosão, porém propiciando, ainda que lento, o desenvolvimento do embrião. Portanto, mesmo sob condições adversas, o desenvolvimento embrionar atinge o estádio de $\mathrm{J}_{2}$ dentro do ovo, porém a eclosão só ocorrerá em condições propícias de temperatura e umidade, às quais o hospedeiro também estará sendo submetido (Campos et al., 2001).

Embora os efeitos da temperatura, umidade e a relação entre a reserva energética corporal e a infetividade já sejam conhecidos (Van Gundy et al., 1967), ainda não foram conciliados de modo prático no controle de nematóides em campo, trazendo, inclusive, questionamentos sobre o potencial do J no solo como inóculo viável, alguns dias após a eclosão. Suprindo ao mesmo tempo, esses dois fatores ambientais limitantes da eclosão (temperatura e umidade), $\mathrm{J}_{2}$ serão liberados no solo e, na falta de hospedeiro, perderão a infetividade. Portanto, o solo e a irrigação poderão ser manipulados abreviando o período de pousio, com maior redução populacional de Meloidogyne spp., propiciando, talvez, a instalação de cultura de ciclo curto e minimizando as perdas na produção pela presença desse nematóide, o que não tem sido enfatizado nas pesquisas em campo.

Desta forma, este trabalho teve como objetivos: estimular a eclosão de $\mathrm{J}_{2}$ de $M$. incognita no campo, manipulando a umidade do solo em épocas de temperaturas altas e, estudar o efeito do revolvimento seguido ou não da irrigação no controle de $M$. incognita em feijoeiro.

\section{MATERIALEMÉTODOS}

O ensaio foi instalado em uma área de 80 ha, com média de $58 \mathrm{~J}_{2}$ de $M$. incognita por $100 \mathrm{~cm}^{3}$ de solo, sob pivô central da Fazenda Gameleira, situada no município de Lagoa Grande, na região do Alto Paranaíba, em Minas Gerais, região de Cerrado em condições de seca e alta temperatura do ar. A identificação da espécie $M$. incognita foi realizada por meio de cortes perineais e de eletroforese de isoenzimas em nematóides coletados em vários locais da área experimental. O solo foi classificado como Neossolo quartzarênico com $86 \%$ de areia, $1 \%$ de silte e $13 \%$ de argila; com $8,43 \%$ e $4,52 \%$ de umidade na capacidade de campo e ponto de murcha permanente, respectivamente. A área foi anteriormente cultivada com feijão, seguida de milho (Zea mays L.). O milho foi colhido três dias antes do estabelecimento do ensaio. Após a colheita, queimouse a palhada para facilitar o revolvimento do solo.

As parcelas foram demarcadas em seqüência, com o auxílio de uma fita métrica, tendo como referência a estrada de acesso ao centro do pivô e o rastro das suas rodas.

Delimitou-se uma área experimental de 50 x 96 m (4.800 $\mathrm{m}^{2}$ ), na qual foram estabelecidas 20 parcelas, cada uma com $120 \mathrm{~m}^{2}$ de área útil. Cada parcela foi dividida em cinco subparcelas de $24 \mathrm{~m}^{2}$ ( $3 \times 8 \mathrm{~m}$ ). Cada subparcela foi dividida em três partes $\left(8 \mathrm{~m}^{2} \mathrm{cada}\right)$, onde foram obtidas as amostras simples (três por subparcela), as quais foram misturadas e delas obtida uma amostra composta de $500 \mathrm{~cm}^{3}$ representativa da subparcela. Portanto, de cada parcela obtiveram-se cinco amostras compostas para análise da população de $M$. incognita.

Os tratamentos seguiram o delineamento experimental inteiramente casualizado com cinco repetições: 1) solo revolvido e irrigado; 2) solo revolvido sem irrigação; 3) solo não revolvido e irrigado; e 4) solo não revolvido sem irrigação, considerado como testemunha.

O experimento foi iniciado em janeiro de 2001, sob intenso veranico. A coleta inicial das amostras e a instalação do ensaio foram realizadas pela manhã, com temperatura do ar em $32^{\circ} \mathrm{Ce} 45 \%$ de UR às 9:00 h. A temperatura na superfície do solo era de $39,5^{\circ} \mathrm{C}$. A $15 \mathrm{~cm}$ de profundidade, a temperatura era de $18^{\circ} \mathrm{C}$, e a umidade de $7 \%$, neste perfil, medida em laboratório. O revolvimento do solo foi executado com trator John Deere 7500, utilizando escarificador de sete hastes na profundidade de $26 \mathrm{~cm}$ a $10 \mathrm{~km} / \mathrm{h}$, seguido da operação de gradagem com grade intermediária de 14 discos de $70 \mathrm{~cm}$, sendo os discos da seção dianteira recortados, e os da traseira lisos, a $13 \mathrm{~cm}$ de profundidade na velocidade de $8 \mathrm{~km} / \mathrm{h}$, deixando o solo bem 
solto e destorroado. Nos tratamentos com irrigação, logo após o revolvimento do solo e naquelas parcelas sem revolvimento, aplicaram-se 10,8 mm de lâmina de água pelo pivô central.

Quatorze dias após a instalação dos tratamentos, realizou-se a semeadura de feijoeiro, cv. Pérola, com semeadoura/adubadoura própria para plantio direto, a qual foi empregada também nas parcelas em que o solo foi revolvido (Tratamentos 1 e 2) não só na área experimental, mas também em toda área do pivô, iniciando-se pela região em que se localizava o experimento, utilizando-se procedimentos de rotina na propriedade.

As amostragens foram feitas a zero, dois e 14 dias após a instalação do ensaio, sempre no mesmo local, com base no mapa experimental, coletando-se o mesmo número de amostras por parcela. Com o auxílio de um enxadão, coletava-se uma fatia de solo de 0 a $20 \mathrm{~cm}$ de profundidade em cada ponto de amostragem, homogeneizava-se, obtendo-se $500 \mathrm{~cm}^{3}$ de solo, que formou a amostra composta. Aos 45 e 90 dias após o plantio, coletaram-se também amostras na rizosfera do feijoeiro, num raio de $20 \mathrm{~cm}$, no perfil de 0 a $30 \mathrm{~cm}$ de profundidade, coletandose solo e todo o sistema radicular de uma planta nessa área, em cada ponto de amostragem. As raízes foram separadas do solo manualmente no campo. No laboratório, foram colocadas em becker de 1 litro com água parada e agitadas levemente para limpeza total, seguindo-se da coloração das massas de ovos por imersão das raízes por 5 min em solução 0,0015\% de Floxina B. A seguir, as raízes foram deixadas sobre papel toalha por 10 min e obtido o peso da matéria fresca, seguida da contagem do número de massas de ovos por sistema radicular. Os sistemas radiculares dos feijoeiros foram, então, cortados em pedaços de $5 \mathrm{~mm}$ para extração de ovos pela técnica de Hussey \& Barker, (1973). Em microscópio (Nikon TMS-F) de objetiva invertida, estimou-se o número de ovos de $M$. incognita por sistema radicular.

Aos 45 dias, a parte aérea dessas plantas foi separada das raízes, colocada em saco de papel e seca por $48 \mathrm{~h}$ a $60{ }^{\circ} \mathrm{C}$, avaliando-se, em seguida, o peso da matéria seca da parte aérea de plantas coletadas em cada ponto de amostragem. Aos 90 dias, avaliou-se a produtividade de grãos, para a qual os feijoeiros foram ceifados e deixados no campo por dois dias para secagem. Em cada parcela experimental avaliou-se a produção de grãos em oito linhas de 0,4 x 2,0 m. A produtividade de grãos por parcela foi corrigida para $13 \%$ de umidade.

A população de $M$. incognita foi avaliada nas amostras de solo obtidas no campo antes e após o plantio do feijoeiro pelo método de Jenkins (1964), extraindo-se $\mathrm{J}_{2}$ livres por 100 $\mathrm{cm}^{3}$ de solo. Para cada amostra composta foram feitas duas extrações. Os $\mathrm{J}_{2}$ foram contados em microscópio de objetiva invertida. $\mathrm{O}$ valor empregado como estimativa do número de $\mathrm{J}_{2}$ por amostra foi a média das duas extrações e o valor anotado em cada parcela foi a média das cinco subparcelas de amostragem.

Na coleta inicial de amostras, bem como aos dois e 14 dias após o estabelecimento dos tratamentos, a população total de nematóides em cada amostra de solo, caracterizada pelo somatório de $\mathbf{J}_{2}$ e ovos viáveis, isto é, com capacidade patogênica, foi estimada através de bioteste com mudas de tomateiro em bandejas de isopor com 72 células. Para isto, 50 $\mathrm{cm}^{3}$ de cada amostra de solo colhida no campo foi misturada com $50 \mathrm{~cm}^{3}$ de substrato Plantmax $\AA$ e colocada em uma célula da bandeja, com duas repetições por amostra. Nestas células, sementes de tomateiro da cv. Santa Clara I 5300 foram semeadas e após a germinação deixou-se apenas uma plântula por célula. As bandejas foram mantidas em casa de vegetação própria para a produção de mudas de hortaliças, com umidade controlada com irrigação por nebulização. Aos 45 dias após a semeadura, as raízes dos tomateiros foram separadas do solo com substrato num becker de 1 litro com água parada. A seguir, todo o sistema radicular foi colocado em solução de Floxina B como descrito anteriormente, seguido da contagem do número de massas de ovos por sistema radicular obteve-se o peso da matéria fresca das raízes.

Os dados obtidos foram submetidos à análise de variância e transformados em $\sqrt{x+0,5}$ conforme a necessidade. As variáveis significativas pelo teste $\mathrm{F}$ foram agrupadas pelo teste de Scott \& Knott (1974). As análises foram realizadas pelo programa estatístico SISVAR.

\section{RESULTADOS E DISCUSSÃO}

\section{Dinâmica do inóculo no solo antes do plantio do feijoeiro}

A densidade populacional e a infetividade da população total de $M$. incognita foram semelhantes em todas as parcelas no momento do revolvimento ou irrigação do solo (0 dia), isto é, antes do estabelecimento dos tratamentos (Figuras 1 e 2).

Dois dias após, o número de $\mathrm{J}_{2}$ no solo e a infetividade em tomateiro da população total nas parcelas revolvidas (R) revolvidas e irrigadas posteriormente (RI) foram menores $(\mathrm{P} \leq 0,01)$ do que naquelas apenas irrigadas (I) e testemunhas (T) (Figuras 1 e 2). O revolvimento, por conseguinte, reduziu a população de $\mathrm{J}_{2}$ devido, talvez, ao maior ressecamento e variação da temperatura do solo. A temperatura ao nível do solo às 14:00 h, no dia da instalação do ensaio chegou a $59^{\circ} \mathrm{C}$, sendo que a $15 \mathrm{~cm}$ de profundidade foi de $23^{\circ} \mathrm{C}$ nas parcelas que receberam revolvimento, contrastando com aquelas não revolvidas, em que a temperatura, nesta mesma profundidade, era de apenas $18^{\circ} \mathrm{C}$. Ornat et. al. (1999) encontraram menor população de $M$. arenaria após dois meses de alqueive em solo revolvido do que em não revolvido. O revolvimento do solo alterou a população de $M$. incognita, diferentemente $(\mathrm{P} \leq 0,01)$ com ou sem irrigação (Figura 1 e 2). Nas parcelas revolvidas a população de $\mathrm{J}_{2}$ no solo (Figura 1) foi maior $(\mathrm{P} \leq 0,01)$ quando se irrigou (RI) devido à indução da eclosão dos juvenis já formados nos ovos, os quais se encontravam em dormência devido à falta de umidade ( Starr, 1993; Jones et al., 1998; Campos et al., 2001). Em condições moderadas de seca no campo, o mecanismo de sobrevivência permite ao nematóide desenvolver-se embrionariamente, mas não eclodir, evitando que o juvenil fique livre no solo antes da presença do hospedeiro (Starr, 1993; Jones et al., 1998; Campos et al. 2001). A população total e infetiva, contudo, avaliada pelo bioteste, foi maior $(\mathrm{P} \leq 0,01)$ nas parcelas $\mathrm{R}$ do que naquelas $\mathrm{RI}$, devido à 
Manejo do solo e da irrigação como nova tática de controle...

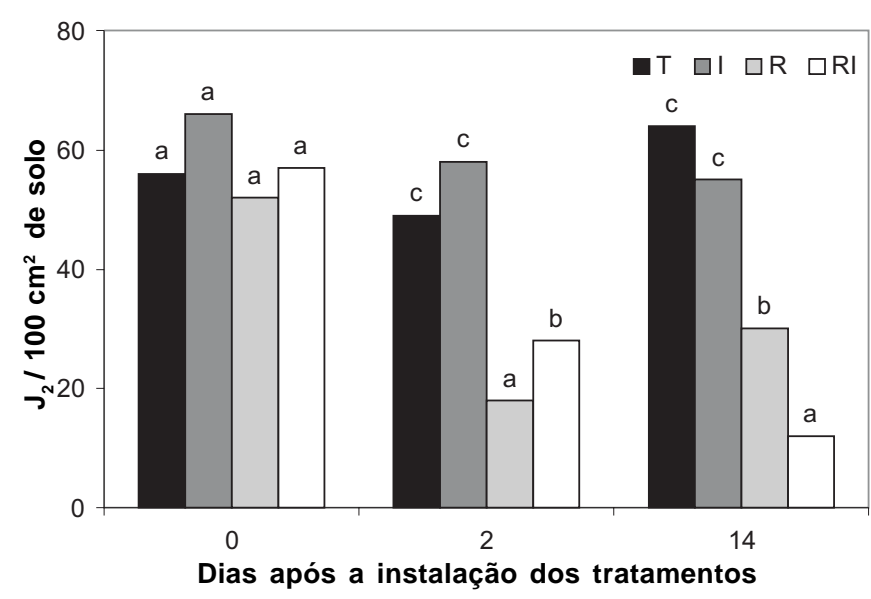

FIG. 1 - Número de juvenis do segundo estádio $\left(\mathrm{J}_{2}\right)$ de Meloidogyne sp. por $100 \mathrm{~cm}^{3}$ de solo colhido no campo no momento ou aos dois e 14 dias após o revolvimento do solo (R) e seguido da irrigação (RI), apenas irrigado sem revolvimento (I), sem irrigação e sem revolvimento (T). Letras diferentes diferem significativamente ao nível de $1 \%$ de significância pelo teste de Scott \& Knott (1974) (CV=10,24\%).

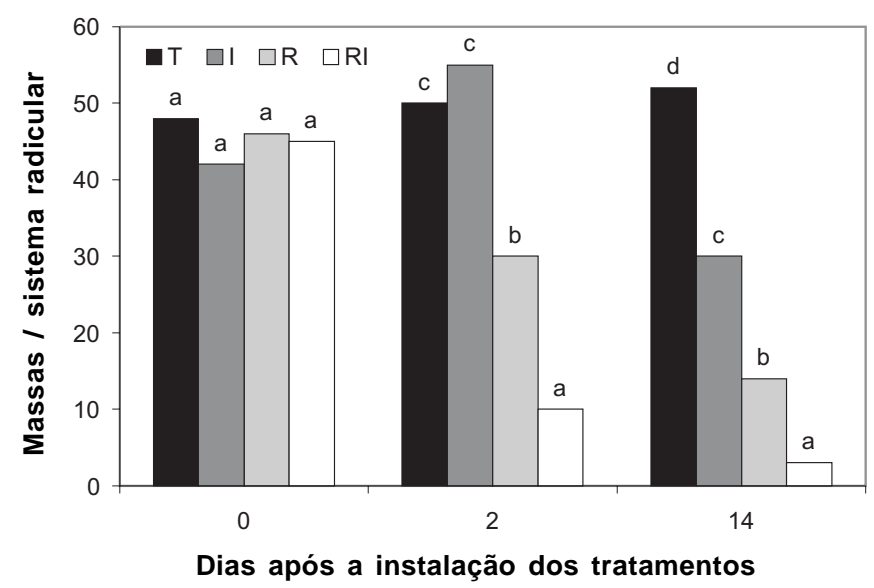

FIG. 2 - População total e infectiva de Meloidogyne incognita no solo, avaliado pelo bioteste com tomateiro (Lycopersicon esculentum), expressa em número de massa de ovos/ planta em solo colhido no campo no momento, dois ou 14 dias após o revolvimento do solo (R) e seguido da irrigação (RI), apenas irrigado sem revolvimento (I), sem irrigação e sem revolvimento (T). Letras diferentes diferem significativamente ao nível de $1 \%$ de significância pelo teste de Scott \& Knott (1974) $(\mathrm{CV}=21,43 \%)$.

maior população de ovos que ainda estava em dormência que resistiram às condições de temperatura e umidade impostas pelo revolvimento, o que não aconteceu nas parcelas RI em que os $\mathrm{J}_{2}$ eclodiram dos ovos tornando assim mais frágeis às condições impostas pelo revolvimento. Starr (1993) encontrou maior redução na população de $M$. incognita em solo úmido com potencial maior do que a $-300 \mathrm{KPa}$. As populações de $\mathrm{J}_{2}$ no solo e a infetividade total foram maiores e semelhantes $(\mathrm{P} \leq 0,01)$ nas parcelas I e T (Figuras 1 e 2).

Quatorze dias após, o efeito do revolvimento do solo nas parcelas R e RI, comparadas com aquelas não revolvidas I e $\mathrm{T}$, na redução de $\mathrm{J}_{2}$ no solo, continuou semelhante à última avaliação relatada anteriormente (Figura 1). Entretanto nas parcelas $\mathrm{R}$ o número de $\mathrm{J}_{2}$ no solo foi maior $(\mathrm{P} \leq 0,01)$ do que naquelas RI (Figura 1), devido, talvez, a dois fatores: maior sobrevivência de embriões viáveis dentro dos ovos que se tornaram $\mathrm{J}_{2}$ livres e a grande redução de $\mathrm{J}_{2}$ ocorrida no período de 12 dias pela privação alimentar prolongada nas parcelas RI. Entretanto, a população total e infetiva avaliada pelo bioteste demostrou bem o efeito isolado ou concomitante, tanto da irrigação como do revolvimento do solo, com todos os tratamentos diferindo-se $(\mathrm{P} \leq 0,01)$ entre si (Figura 2). Insere-se aqui outro componente explicativo, isto é, a perda da infetividade do $\mathrm{J}_{2}$ no campo, pois, com exceção da testemunha todos os tratamentos tiveram a população total e infetiva (Figura 2) menor do que a do $\mathrm{J}_{2}$ no solo (Figura 1). Segundo Van Gundy et al. (1967), a capacidade de infecção do $\mathrm{J}_{2}$ de $M$. javanica diminui com a perda da mobilidade e das reservas energéticas do corpo constituídas por lipídio que perfazem $30 \%$ do corpo do $\mathrm{J}_{2}$ imediatamente após a saída do ovo. Essas reservas são gastas rapidamente a temperaturas altas e preservadas a temperaturas baixas. A $29^{\circ} \mathrm{C}$ a atividade muscular e a respiração requerem grande utilização de energia pelo nematóide (Goodell \& Ferris, 1989). A perda de 50-60\% dessa reserva lipídica leva o $\mathrm{J}_{2}$ a perda da infetividade (Van Gundy et. al., 1967). A irrigação mesmo sem revolvimento do solo reduziu $(\mathrm{P} \leq 0,01)$ a população total e infetiva comparada com a testemunha (Figura 2), comprovando experimentalmente a hipótese da efetividade do pousio úmido agora testada no campo, porém com eficácia bem superior $(\mathrm{P} \leq 0,01)$ quando o terreno foi revolvido e irrigado (RI). Melhor eficácia deste tratamento poderá ser alcançada com o aumento da sua freqüência em diferentes intervalos de tempo, o que pode constituir-se em novas pesquisas, também para diferentes tipos de solo.

Barker \& Koenning (1998) citaram publicação de Tyler (1933), sugerindo o alqueive úmido durante o período quente, num terreno sem ervas daninhas, como uma tentativa para erradicar os nematóides de galhas de áreas infestadas. Towson \& Apt (1983) sugeriram, também, como promissora e de aplicação prática, a pré-irrigação semanal durante um mês antes do plantio para a redução significativa da população dos nematóides de galhas e reniforme do abacaxi [Ananas comosus (L.) Merr]. Apt (1976), estudando a sobrevivência do nematóide reniforme em solo infestado colhido no campo e submetido a diversas condições de umidade em períodos variáveis de tempo, sugeriu, baseado nos seus dados em laboratório, que a irrigação poderia no campo ser mais eficaz na redução populacional do Rotylenchulus reniformis Linford \& Oliveira durante os quatro primeiros meses do alqueive. Goodell \& Ferris (1989), estudando a influência de fatores ambientais na eclosão e na sobrevivência de $M$. incognita, concluíram que seus resultados dão suporte ao conceito do "alqueive úmido", onde a aplicação de água no local de plantio na ausência do hospedeiro pode ser usada para aumentar a mortalidade de $M$. incognita.

Portanto, a irrigação pode constituir em nova estratégia de manejo de fitonematóides para abreviar ainda mais o período 
de alqueive aumentando a eficácia na redução populacional de Meloidogyne spp. Tem-se, tradicionalmente, recomendado três-quatro meses de alqueive, com redução de $90 \%$ da população de $M$. incognita (Huang \& Porto, 1988) e de seis meses para redução a nível não detectável da população de $M$. javanica (Campos, 1987). Com a irrigação esse período poderá ser reduzido.

Ornat et al. (1999) reduziram a população de $M$. incognita em 99,98\% após oito semanas de alqueive no verão. Essa eficácia pode ter sido alcançada por esses autores devido a chuvas e altas temperaturas no período.

Contudo o revolvimento $(\mathrm{R})$ foi melhor $(\mathrm{P} \leq 0,01)$ na redução da patogenicidade do $\mathrm{J}_{2}$ do que quando apenas se irrigou o solo (I) (Figura 2). Comprovando-se também que parte da população de $\mathbf{J}_{2}$ detectada pelo método de Jenkins (1964) (Figura 1) não era mais infetiva, já que populações semelhantes $(\mathrm{P} \leq 0,01)$ de $\mathrm{J}_{2}$ detectadas nas parcelas $\mathrm{T}$ e naquelas parcelas I (Figura 1) foram diferentes em patogenicidade no bioteste (Figura 2).

A queima da palhada do milho realizada antes do estabelecimento do ensaio favoreceu o revolvimento do solo, e evitou o surgimento de ervas daninhas na área experimental, evitando o aumento da população de nematóides, o que poderia diminuir o efeito dos tratamentos aplicados.

\section{Evolução da população de $M$. incognita no campo}

O feijoeiro, considerado bom hospedeiro, proporcionou a evolução populacional infetiva de $\mathrm{J}_{2}$ de $M$. incognita em proporções semelhantes aos níveis detectados nas parcelas 14 dias após os manejos do solo pelo revolvimento e/ou irrigação como descritos anteriormente (Figura 2). Os números de $\mathrm{J}_{2}$ no solo, ovos e massas de ovos por planta avaliados aos 45 dias, e de ovos/planta aos 90 dias após o plantio do feijoeiro foram mais baixos $(\mathrm{P} \leq 0,01)$ nas parcelas $\mathrm{RI}$ do que nas demais (Figuras 3A, B e C). Nessas parcelas o inóculo no solo era também o mais baixo $(\mathrm{P} \leq 0,01)$ dentre todos os demais no final dos 14 dias de pousio (Figura 1). Apenas o revolvimento do solo foi menos eficaz do que o tratamento, revolvimento seguido de irrigação, porém reduziu $(\mathrm{P} \leq 0,01)$ o número de $\mathrm{J}_{2}$ no solo, ovos e massa de ovos/planta aos 45 e 90 dias após o plantio do feijoeiro comparado com a irrigação sem revolvimento e a testemunha (Figuras 3A, B e C). Contudo, nas parcelas I e nas $\mathrm{T}$, os números de $\mathrm{J}_{2}$ no solo, ovos e massa de ovos / planta aos 90 dias e de ovos e massa de ovos / planta aos 45 dias após o plantio do feijoeiro foram semelhantes $(\mathrm{P} \leq 0,01)$ (Figuras $3 \mathrm{~A}, \mathrm{~B}$ e C), indicando menor eficácia da irrigação sem o revolvimento do solo como forma de manejo populacional de $M$. incognita. Nessa condição do solo sem distúrbio a irrigação pode ter reduzido um pouco mais a temperatura no perfil e mantida a umidade adequada para a sobrevivência de $M$. incognita por período mais longo no solo. Apesar de baixa, alguma eficácia ocorreu na redução da população de $M$. incognita nas primeiras fases do desenvolvimento vegetativo do feijoeiro quando apenas se irrigou, já que o número de $\mathrm{J}_{2}$ no solo foi menor $(\mathrm{P} \leq 0,01)$ do que na testemunha, aos 45 dias após o plantio. Melhor eficácia desse tratamento poderia ter sido detectada,
A

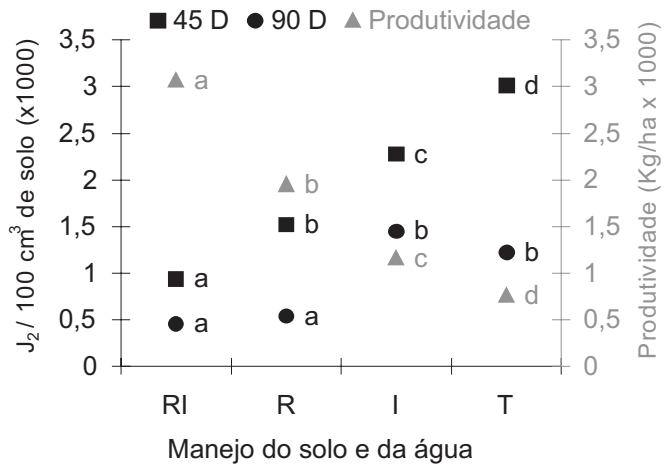

$C V=11,52 \%$

$C V=11,68 \%$

B

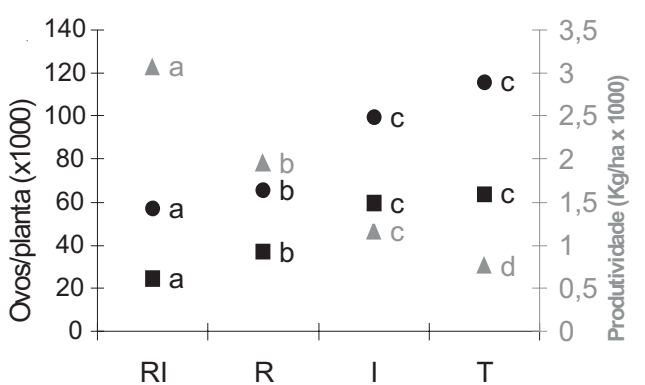

$C V=10,33 \%$

C

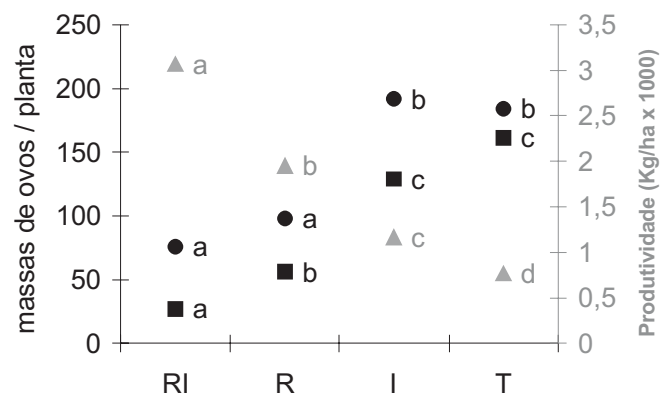

$\mathrm{CV}=11,78 \%$

FIG. 3 - Número de juvenis do segundo estádio $\left(J_{2}\right)$ por $100 \mathrm{~cm}^{3} \mathrm{de}$ solo (A), de ovos (B) e de massas de ovos por planta (C) de Meloidogybe incognita, por planta de feijoeiro (Phaseolus vulgaris), obtidos no campo em solo revolvido (R), seguido de irrigação (RI), apenas irrigado sem aração (I), ou sem aração e sem irrigação (T), aos 45 e 90 dias após a semeadura. Produtividade em quilos $(\mathrm{kg})$ por hectare. Letras diferentes diferem estatisticamente ao nível de $1 \%$ de significância pelo teste de Scott \& Knott (1964).

se avaliações populacionais tivessem sido feitas nas três primeiras semanas após o plantio. Redução populacional de Meloidogyne spp. nas fases iniciais do desenvolvimento vegetativo de cultura anual pode incrementar seu potencial de produção (Huang \& Porto, 1988).

Em resumo, nas condições deste experimento, das duas formas de manejo estudadas, o revolvimento foi o único que isoladamente reduziu eficazmente a população de $M$. incognita. A irrigação após o revolvimento, entretanto, tem efeito sinergístico na redução populacional desse nematóide. A irrigação sem revolvimento teve pequeno efeito reducional da população desse nematóide. 


\section{Desenvolvimento e produção de feijoeiro no campo}

Embora o peso da matéria fresca da parte aérea dos feijoeiros das parcelas RI fosse maior do que naqueles das parcelas R, não ocorreu diferença estatística significativa entre elas (Tabela 1); contudo, foram bem maiores $(\mathrm{P} \leq 0,01)$ do que o peso da matéria fresca da parte aérea dos feijoeiros de parcelas I e das T. O menor $(\mathrm{P} \leq 0,01)$ crescimento vegetativo, dentre todos os tratamentos, ocorreu nas parcelas $\mathrm{T}$ (Tabela 1). A irrigação sem revolvimento aumentou $(\mathrm{P} \leq 0,01)$ o peso da parte aérea em relação à testemunha (Tabela 1$)$. $\mathrm{O}$ peso da parte aérea foi inversamente proporcional à infetividade do inóculo na época da semeadura, com correlação de $-0,85$. O peso da matéria fresca das raízes dos feijoeiros das parcelas $\mathrm{RI}$ e $\mathrm{R}$ foi semelhante $(\mathrm{P} \leq 0,01)$; contudo, maior $(\mathrm{P} \leq 0,01)$ do que aqueles das parcelas I e T (Tabela 1) aos 90 dias após a semeadura, embora nenhuma diferença entre os tratamentos ocorresse aos 45 dias para o peso da matéria fresca das raízes (Tabela 1). A secagem das raízes não contribuiu para a diferenciação dos tratamentos. Maior população de $M$. incognita na semeadura (Figura 2) concorreu para a redução do sistema radicular do feijoeiro. Os nematóides do gênero Meloidogyne, em associação com o sistema radicular do feijoeiro, causam decadência geral das plantas, com amarelecimento da folhagem, redução das raízes laterais, formação de grandes galhas, queda na produção, podendo levar a morte da planta (Lordello \& Santos, 1960).

A produção dos feijoeiros no campo foi inversamente proporcional à população de $M$. incognita, tanto na semeadura (Figuras 1 e 2) quanto aos 45 e 90 dias após (Figura 3) com uma correlação de $-0,90$ para $\mathbf{J}_{2}$ no solo na época da semeadura e de $-0,88$ para população infetiva no mesmo período. Todos os tratamentos diferiram-se entre si e produziram mais $(\mathrm{P} \leq 0,01)$ do que a testemunha, na qual se empregou a técnica do plantio direto.

O revolvimento seguido da irrigação (RI) proporcionou a maior $(\mathrm{P} \leq 0,01)$ produtividade com $3.065 \mathrm{~kg} / \mathrm{ha}$ (Tabela 1$)$, cerca de quatro vezes àquela produzida pela testemunha, com ótimo desenvolvimento da parte aérea, contrastando com o desenvolvimento vegetativo reduzido na testemunha pelo plantio direto.

TABELA 1 - Peso da matéria fresca de raízes de feijoeiros (Phaseolus vulgaris) colhidas aos 45 e 90 dias após a semeadura, e da matéria fresca da parte aérea aos 45 dias e produtividade da cultura em áreas apenas revolvidas (R), apenas irrigadas (I), revolvidas e irrigadas (RI) e não revolvidas e nem irrigadas $(\mathrm{T})$

\begin{tabular}{|c|c|c|c|c|}
\hline \multirow{2}{*}{$\begin{array}{l}\text { Manejo } \\
\text { do solo e } \\
\text { da água }\end{array}$} & \multicolumn{2}{|c|}{$\begin{array}{l}\text { Peso de raízes }(\mathrm{g}) \\
\quad(\mathrm{CV}=\mathbf{2 3}, \mathbf{4 1 \%} \%)\end{array}$} & \multirow{2}{*}{$\begin{array}{c}\begin{array}{c}\text { Peso da parte } \\
\text { Aérea }(g) \\
(\mathrm{CV}=13,70 \%)\end{array} \\
45 \text { dias }\end{array}$} & \multirow{2}{*}{$\begin{array}{c}\text { Produtividad } \\
\text { Kg/ha } \\
(\mathrm{CV}=11,68 \%) \\
90 \text { dias }\end{array}$} \\
\hline & 45 dias & 90 dias & & \\
\hline RI & $5,1 \mathrm{~A}$ & $10,7 \mathrm{~A}$ & $13,1 \mathrm{~A}$ & $3065 \mathrm{~A}$ \\
\hline $\mathbf{R}$ & $4,7 \mathrm{~A}$ & $10,5 \mathrm{~A}$ & $12,0 \mathrm{~A}$ & 1952 B \\
\hline I & $4,3 \mathrm{~A}$ & $7,1 \mathrm{~B}$ & $9,4 \mathrm{~B}$ & $1161 \mathrm{C}$ \\
\hline $\mathbf{T}$ & $4,9 \mathrm{~A}$ & $7,4 \mathrm{~B}$ & $7,2 \mathrm{C}$ & $765 \mathrm{D}$ \\
\hline
\end{tabular}

O revolvimento e a irrigação, isoladamente, proporcionaram aumentos de 2,55 e 1,52 vezes (Tabela 1), respectivamente, a produção na testemunha, demonstrando, portanto menor eficácia do que aquela obtida pelo efeito concomitante dos dois manejos, isto é, revolvimento seguido da irrigação. Portanto, aumentos expressivos de produtividade e de redução populacional de $M$. incognita do feijoeiro podem ser alcançados com 14 dias de pousio desde que o solo infestado seja revolvido e irrigado em período seco e de temperatura elevada no campo.

\section{REFERÊNCIAS BIBLIOGRÁFICAS}

AGUDELO, F.V. de. Nematodes. In: Schwartz, H.F. \& Galvez, G.E. (Eds.). Bean production problems: disease, insect, soil and climatic constraints of Phaseolus vulgaris. Cali. CIAT. 1980. pp.315-326.

APT, W.J. Survival of reniforme nematodes in desiccated soils. Journal of Nematology 8:278. 1976.

BARKER, K.R. \& KOENNING, S.R. Developing sustainable systens for nematode management. Annual Review of Phytopatology 36:165205. 1998.

CAMPOS, V.P. Sobrevivência de Meloidogyne javanica no solo e em raízes de tomateiros. Summa Phytopathologica 13:191-196. 1987.

CAMPOS, V.P., CAMPOS, J.R., SILVA, L.H.C.P. \& DUTRA, M.R. Manejo de nematóides em hortaliças. In: Silva, L.H.C.P., Campos, J.R. \& Nojosa, G.B.A. (Eds.) Manejo integrado: doenças e pragas em hortaliças. Lavras. Editora UFLA. 2001. pp.125-158.

CHITWOOD, D.J. Biosyntesis. In: Perry, R.N. \& Wright, D.J. (Eds.). The physiology and biochemistry of free-living and plant-parasitic nematodes. London. CAB International. 1998. pp.303-330.

DI VITO, M.N.G. \& CARELLA, A. Population densities of Meloidogyne incognita and yield of Capsicum annuum. Journal of Nematology 17:45-49. 1985.

DUTRA, M.R. \& CAMPOS, V.P. Efeito do preparo do solo na população dos nematóides das galhas (Meloidogyne spp.). Resumos, 21ํㅡㄹ Congresso Brasileiro de Nematologia, Maringá, SP. 1998. p.45.

FREIRE, F.C.O. \& FERRAZ, S. Nematóides associados ao feijoeiro, na Zona da Mata, Minas Gerais, e efeitos do parasitismo de Meloidogyne incognita e M. javanica sobre o cultivar 'Rico 23'. Revista Ceres 24:141-149. 1977.

GOODELL, P.B. \& FERRIS, H. Influence of environmental factors on the hatch and survival of Meloidogyne incognita. Journal of Nematology 21:328-334. 1989.

HUANG, S.P. \& PORTO, M.V.B. Efeito do alqueive na população dos nematóides das galhas e na produção de cenoura. Fitopatologia Brasileira 13:377-381. 1988.

HUSSEY, R.S. \& BARKER, K.R. A comparison of methods of collecting inocula for Meloidogyne spp., incluiding a new technique. Plant Disease Reporter 57:1025-1028. 1973.

JENKINS, W. R. A rapid centrifugal-flotation technique for separating nematodes from soil. Plant Disease Reporter 48:692. 1964.

JONES, P.W., TYLKA, G.L. \& PERRY, R.N. Hatching. In: Perry, R.N. \& Wright, D.J. (Eds.). The physiology and biochemistry of free-living and plant parasitic nematodes. London. CAB International. 1998. pp.181-212.

LEE, D.L. \& ATKINSON, H.J. Physiology of nematodes. New York. 
Columbia University Press. 1977.

LORDELLO, L.G.E. \& SANTOS, C.F.O. Incidência de nematóides em culturas de feijão. O Biológico 26:213-217. 1960.

ORNAT, C., VERDEJO-LUCAS, S., SORRIBAS, F.J. \& TZORTZAKAKIS, E. A. Effect of fallow and root destruction on survival of root-knot and root-lesion nematodes in intensive vegetable cropping systems. Nematropica 29:5-16. 1999.

PAULA JUNIOR, T.J. de \& ZAMBOLIM L. Doenças. In: Vieira, C., Paula Junior, T.J., Borém, A. (Eds.) Feijão: aspectos gerais e cultura no Estado de Minas Gerais. Viçosa. Editora UFV. 1998. pp. 373-433.

SCOTT, A.J. \& KNOTT, M. A cluster analysis method for grouping means in the analysis means in the analysis of variance. Biometrics 30:507-512. 1974.

STARR, J.L. Recovery and longevity of Egg Masses of Meloidogyne incognita during simulated winter survival. Journal of Nematology
25:244-248. 1993.

TOWSON, A.J. \& APT, W.J. Effect of soil water potential on survival of Meloidogyne javanica in fallow soil. Journal of Nematology 15:110115. 1983.

VAN GUNDY, S.D., BIRD, A.F. \& WALLACE, H.R. Aging and starvation in juvenile or Meloidogyne javanica and Tylenchulus semipenetras. Phytopathology 57:559-571. 1967.

VIEIRA, C. Doenças e pragas do feijoeiro. Viçosa. Editora UFV. 1993.

VRAIN, T.C. \& BARKER, K.R. Influence of low temperature on development of Meloidogyne incognita and M. hapla eggs in egg masses. Journal of Nematology 10:311-313. 1978.

WALLACE, H. R. Undulatory locomotion of the plant-parasitic nematodes, M. incognita. Parasitology 58: 377-391. 1968.

ZAUMEYER, W.J. \& THOMAS, H.R. A monografic study of bean diseases and methods for their control. Washington. U.S.D.A. 1957. 